\title{
Health Insurance and Health
}

\section{Jingxian $\mathbf{W U}^{1,2 *}$}

${ }^{1}$ Xi'an Jiaotong University, China

${ }^{2}$ City University of Hong Kong, China

*Corresponding author: Jingxian WU, Xi'an Jiaotong University, No. 28 West

\section{Editorial}

Volume 2 Issue 6

Received Date: October 25, 2019

Published Date: November 01, 2019

DOI: $10.23880 /$ jqhe- 16000142

Xianning Road, Xi'an, P.R. China, Email: jxwu0625@163.com

\section{Editorial}

According to the World Health Organization Report, "promoting and protecting health is essential to human welfare and sustained economic and social development" [1]. Health not only matters for everyone, but also for the whole nation. Given the highest priority to population health for socioeconomic development, national health security should be a profound political issue as national governments are required to satisfy their people's health expectations and reach Universal Health Coverage (UHC) by establishing universal health care systems based on circumstances within the country.

Health insurance is one of the most typical institutional arrangements towards UHC. Health insurance is originally an insurance that covers the whole or a part of the risk of a person incurring medical expenses, spreading the financial risk of diseases over a large number of persons. In other words, it is designed to positively affect population health by removing financial risks and enhancing access to healthcare services in case of illness risk [2]. This reasoning about the positive effects of health insurance on health has been supporting the universal coverage of public or social health insurance programs in the worldwide. Plenty of evidence on the expansion of public or social health insurance schemes in both developed countries (such as the Medicare and Medicaid in the United States, German Statutory Health Insurance) and developing countries (such as Chinese social health insurance, Vietnam national health insurance, and Indian national health insurance) has suggested that the broader coverage of these health insurance programs could, in most cases, improve general access to necessary medical services, from which the poor benefit the most in terms of health maintenance [3].

With the increasing demand for health care and health, the original function of health insurance (namely, offering economic compensation for medical expenses after the insured falls ill) has been urged to be developed into a comprehensive health management and health promotion, including but not limited to prevention exante illness and treatment ex-post illness. For example, one recent goal of the Affordable Care Act (ACA) in the US is to increase preventive care and improve health behaviors by expanding access to health insurance [4]. In German, the well-known "bonus program" and other various financial and non-financial incentive measures have been implemented together with its social health insurance reform to enhance individual health management by encouraging all citizens to be engaged in disease prevention and health promotion [5]. Apart from the compensation on illness treatment, the future health insurance reform is supposed to attach critical importance to incentives on illness prevention. This lays a foundation not only for the cost containment of the health insurance system, but also for the health outcome improvement of the whole nation.

\section{References}

1. World Health Organization (2010) World Health Report 2010-Health systems financing: The path to universal coverage.

2. Acharya A, Vellakkal S, Taylor F, Masset E, Satija A, et al. (2013) The impact of health insurance schemes for the informal sector in low-and middle-income countries: a systematic review. The World Bank Research Observer 28(2): 236-266.

3. Levy H, Meltzer D (2008) The impact of health insurance on health. Annual Review of Public Health 29: 399-409.

4. Simon K, Soni A, Cawley J (2017) The impact of health insurance on preventive care and health behaviors: 


\section{Journal of Quality in Health Care \& Economics}

evidence from the first two years of the ACA Medicaid expansions. Journal of Policy Analysis and Management 36(2): 390-417.

5. Stock S, Stollenwerk B, Klever Deichert G, Redaelli M, Büscher G, et al. (2008) Preliminary analysis of short term financial implications of a prevention bonus program: First results from the German statutory health insurance. Int J Public Health 53(2): 78-86. 